Sociohistórica, n 42, e057, 2do. Semestre de 2018. ISSN 1852-1606

Universidad Nacional de La Plata.

Facultad de Humanidades y Ciencias de la Educación.

Centro de Investigaciones Socio Históricas

\title{
Escena con un militante de izquierda: aproximaciones sobre su forma de hacer política
}

Martina Moriconi

Instituto de Altos Estudios Sociales (IDAES). Universidad Nacional de San Martín (UNSAM), Argentina martina.moriconi1@gmail.com

Cita recomendada: Moriconi, M. (2018). Escena con un militante de izquierda: aproximaciones sobre su forma de hacer política. Sociohistórica, 42, e057. https://doi.org/10.24215/18521606e057

Recibido: : 24 noviembre 2017 - Aceptado: 02 mayo 2018 - Publicado: 3 diciembre 2018

(c) (1) (2) (2)

Esta obra está bajo licencia Creative Commons Atribución-NoComercial-CompartirIgual 4.0 Internacional http://creativecommons.org/licenses/by-nc-sa/4.0/deed.es AR 


\section{Escena con un militante de izquierda: aproximaciones sobre su forma de hacer política}

Scene with a political activist of left: approximations about his way of doing politics

Martina Moriconi

Instituto de Altos Estudios Sociales (IDAES). Universidad

Nacional de San Martín (UNSAM), Argentina

martina.moriconi1@gmail.com

\section{Resumen:}

Este trabajo se propone reflexionar sobre la forma de militancia de Marcos, un obrero fabril, delegado sindical y militante trotskista. Para ello, se trabajará con registros etnográficos y fragmentos de entrevistas. Asimismo, se fundamentará la importancia de analizar los bares como lugares centrales para nuestro interlocutor y, a través de los cuales, se vislumbrarán otras facetas de su modo de hacer política. Entonces, situados en un bar matancero en pleno contexto electoral, veremos cómo las transformaciones en la militancia, que Marcos señalaba discursivamente, se pondrían en evidencia allí y me interpelarían en mi rol de investigadora. Por lo tanto, poner en práctica la reflexividad será una excelente vía para aprender aún más de su forma de militancia. Así, concluiremos en la necesidad de matizar aquellas visiones que reconstruyen las prácticas de militancia trotskista a partir, esencialmente, de la discusión política.

Palabras clave: Militancia, Sindicalismo de base, Reflexividad, Campaña electoral, La Matanza.

\section{ABstract:}

The purpose of this paper is to reflect on the form of militancy of Marcos, a factory worker, union delegate and trotskyist militant. For this, we will work with ethnographic records and fragments of interviews. Likewise, we will demonstrate the importance of analyzing bars as central places for our interlocutor, and through them, other facets of their way of doing politics will be apparent. Then, located in a Matanza's bar in the electoral context, we will see how the transformations in militancy, which Marco pointed out discursively, would be evident there and would interpellate me in my investigative role. Therefore, putting reflexivity into practice will be an excellent way to learn even more about its form of militancy. Thus, we will conclude on the need to clarify those visions that reconstruct the practices of Trotskyist militancy based, essentially, on political discussion.

KEYwords: Militancy, Syndicalism, Electoral campaign, Reflexivity, La Matanza.

\section{INTRODUCCIÓN}

A partir del 2003, la economía argentina logró superar, paulatinamente, los desbarajustes provocados por la crisis de 2001 y comenzar un ciclo de reactivación, que tuvo a la industria manufacturera como uno de los sectores más favorecidos con un incremento considerable de mano de obra asalariada (Benza, 2016). En este contexto, emergió un conjunto de experiencias de sindicalización, y más precisamente de bases, al interior de un importante número de fábricas que buscaban tanto mejorar sus condiciones de trabajo como disputar la representación a los sindicatos (Pereyra, 2016). Por supuesto que el crecimiento de este fenómeno atrajo la atención de las Ciencias Sociales y, por lo tanto, hoy nos encontramos frente a un interesante y diverso corpus de publicaciones académicas respecto a la temática (Varela, 2015; Abal Medina, 2014; Aiziczon, 2009; Ventrici, 2012; Senen González \& Del Bono, 2013) que fueron fundamentales al momento de comenzar mi investigación sobre el caso de una fábrica ubicada en el distrito bonaerense de La Matanza.

Ni bien entré en contacto con delegados de la comisión interna, a mediados de 2016, para entender su mirada sobre el proceso de organización gremial que había comenzado doce años atrás y aún se mantenía en pie, entendí que Marcos - quien había sido el principal impulsor- continuaba siendo una persona clave 
del entramado (Elias, 2008). Y también que dada la primacía de enfoques sobre la temática que resaltaba la imagen del actor colectivo, resultaba valioso centrarnos a reflexionar desde la perspectiva de Marcos para recuperar, tal como señalan Semán y Ferraudi Curto (2013), la noción de persona (Goldman, 1999) como filtro analítico y, así, dar cuenta de politicidades singulares. De esta manera, luego de una serie de entrevistas en profundidad y de acompañarlo en diversas actividades de su cotidiano como militante de un partido de izquierda, quedaba en claro que, si bien el espacio gremial y el partidario eran lugares fundamentales de sociabilidad para comprender su forma de hacer política, también había otros a los que había que prestar atención porque, como me mostraba con su accionar, un militante como él se es las veinticuatro horas del día y de variadas formas. En este sentido, los distintos bares en los que conversamos, iluminarían aspectos, hasta aquí, opacos.

En efecto, a lo largo de estas páginas me propondré comprender, desde la perspectiva de mi interlocutor, su modo de interpretar la militancia y también algunas de sus transformaciones. Con respecto a ello, nos detendremos en aquellos cambios de la militancia que pude rastrear no sólo en su discurso sino también en la práctica. Por esta razón, nos centraremos en los acontecimientos ocurridos en los bares, ya que ahí podía observar que su modo de relacionarse y su forma de interpretar las estrategias para acrecentar el volumen de electores y simpatizantes a través de las redes sociales y del diario digital tenía su correlato en estos espacios. Por consiguiente, en primer lugar, nos enfocaremos en iluminar la potencia analítica de estos espacios para la comprensión de un determinado tipo de sociabilidades cotidianas. Luego, trazaremos líneas de continuidad en su relato sobre algunos elementos que buscan aggiornar la política partidaria para que, así, la discusión política no se convierta en el camino exclusivo para ganar adeptos. En tercer término, a raíz de un cruce verbal entre Marcos y la dueña de un bar, analizaremos las dificultades que encuentra nuestro militante en determinados contextos de la política nacional donde las evaluaciones morales cobran protagonismo. En cuarto lugar, será el momento de detenernos en el vínculo con mi interlocutor -en mi rol de investigadora- para, a partir de un análisis reflexivo, continuar desandando aspectos que retratan su modo de militancia. Posteriormente, en base al recorrido trazado sobre las singularidades de Marcos, sostendremos la necesidad de repensar, constantemente, las tipologías de la militancia. Por último, dejaremos sentada una breve consideración final. En suma, a partir del análisis descriptivo y reflexivo, intentaremos dar cuenta de la politicidad de Marcos desde su condición de obrero fabril, delegado, militante y matancero, para así complejizar la figura del militante trotskista hegemonizada por la práctica de la discusión política (Rosato y Quirós, 2004; Quirós, 2005).

\section{LA RIQUEZA ANALÍTICA DE LOS BARES}

Revisando mis notas de campo, pude observar que todos los lugares que Marcos había elegido para hacer las primeras entrevistas y tener las siguientes charlas eran significativos para él. Los encuentros iniciales fueron en un pequeño bar cerca de su lugar de trabajo. Ni bien entramos afirmó "acá nos empezamos a juntar para organizarnos": así hacía referencia a las primeras reuniones que tenían de manera "clandestina” con los trabajadores más cercanos a la salida de la fábrica. La siguiente vez, me convocó en una confitería-pizzería grande ubicada en la rotonda de San Justo que, a su vez, cuenta con un lavadero de autos y canchitas de futbol. Allí señaló: "cuando éramos más de veinte nos empezamos a juntar acá porque en el otro bar ya no entrábamos”. Además, ahí mismo jugaban, en muchas oportunidades, al futbol y, a la vez, continuaban siendo las reuniones de la agrupación fabril. En otra oportunidad, nos encontramos para ir a almorzar, en el camino me contó que íbamos a ir al restaurante de unos "viejitos" que se habían casado poco tiempo antes y él había sido el testigo de casamiento. Al abrir la puerta, Adela y Emilio -de setenta años aproximadamente- nos recibieron con mucho afecto, Marcos les comentó sobre mi trabajo de investigación y ellos inmediatamente me mostraron una foto -enmarcada y colgada en una de las paredes principales- en la que estaba Marcos y otro de los delegados de la fábrica. Adela me relató detalles del reciente casamiento y me comentó que 
Marcos fue el testigo porque desde que lo conocieron lo quisieron mucho. Así, rápidamente comprendí que la relación entre ellos se creó en los ratos que él iba a almorzar y que a través de esos mediodías logró "hacerse querer”. Por supuesto que estos atributos personales también se podían apreciar en las movilizaciones de su partido a las que lo acompañé y, asimismo, en los relatos de sus compañeros de fábrica que mencionaban la importancia que tuvo el ingreso de él a la planta para que lograran organizarse y mejorar sus condiciones de trabajo. Incluso, muchos de ellos sostuvieron que con la huelga que hicieron en protesta por el despido de Marcos en 2005 empezó "la historia" de la militancia gremial.

Posteriormente, en uno de los últimos encuentros, Marcos me avisó que íbamos a ir a un bar cercano al de la rotonda de San Justo porque allí se comía mejor y, por sobre todo, era más barato. Al llegar, ya estaba a los abrazos con Rosa, la dueña, de unos cincuenta años. Nos sentamos en una de las cuatro mesas que había en el lugar, Rosa le preguntó si iba a comer lo de siempre a lo que Marcos asintió. Con el entusiasmo de la dueña al verlo, su forma de abrazarlo y la complicidad entre ambos ya estaba en claro que Marcos tenía una nueva amiga. Algo deslumbrada por su capacidad de generar lazos de confianza en los lugares que transitaba para comer a la salida de la fábrica, le pregunté si había dejado de concurrir a lo de Adela y Emilio y me respondió que tuvieron que cerrar el bar porque no pudieron afrontar el aumento de las tarifas decretado por el gobierno nacional, pero que seguía en contacto. Cabe aclarar que, a diferencia de otros trabajadores que a la salida de la fábrica vuelven a sus casas para estar con sus familias, Marcos, que alquila una casa con cuatro "compañeros del partido", generalmente aprovecha para comer algo "al paso" y abocarse a actividades de la militancia. Ante mis ojos, su ritmo de vida tenía una gran intensidad y se puede ver, desde su relato, que para otros militantes también: "Mis compañeros me dicen vos no tenés vida, te vas a la reunión, a la marcha, de la reunión a la asamblea. Esto es parte de mi vida, no me molesta, lo disfruto" (Marcos, comunicación personal, 1 de agosto de 2016).

Ese día mi pretensión era saber con más detalle sus inicios en la militancia porque si bien me había comentado sobre su ingreso al partido a los diecisiete años, en la escuela técnica secundaria a la que iba, no sabía mucho más de esa etapa y dado que ya habían transcurrido más de veinte años en esa organización partidaria, consideraba valioso contar con su relato aquel comienzo. Antes de prender el grabador para iniciar la entrevista, me contó sobre la campaña política de las $\mathrm{PASO}^{1}$, en la que iba de precandidato a Diputado Nacional por la provincia de Buenos Aires en el Frente de Izquierda y de los Trabajadores (FIT). En esa breve charla, marcaba transformaciones en la forma de hacer la campaña política, que minutos después una discusión en el bar pondrían en evidencia. Así, entendí que mi preocupación por comenzar la entrevista para indagar en sus experiencias pasadas no era lo realmente importante en ese momento, sino que debía poner mayor atención en su comportamiento ante esas situaciones cotidianas. En esos instantes de interacción en el bar entre él y las demás personas estaba la clave, que, hasta aquí, no consideraba de gran relevancia para mi trabajo de campo porque, erróneamente, entendía que situaciones como las de movilizaciones políticas, cortes de ruta o bien acompañarlo a pegar carteles en la calle o asistir a reuniones en el local eran más interesantes etnográficamente. Claro que, siguiendo a Marc Abélês (1997), las movilizaciones permitían ser comprendidas como rituales de la vida política, con sus simbolismos presentes en las banderas, consignas, cánticos. Y, a la vez, posibilitaban captar las interacciones entre los manifestantes-militantes y su manipulación de los objetos de valor simbólico. Por esta razón, las entrevistas en los bares no me parecían, primeramente, un buen lugar porque las consideraba como ajenos a los espacios cotidianos de mi interlocutor.

Más tarde, fui consciente de que en mi interpretación rondaba una noción cercana a la de no-lugar de Marc Augé (1992), sin aún haberla podido leer, donde los "lugares" son definidos como espacios de identidad, relacionales e históricos y, por ende, los que no cuentan con estos atributos son caracterizados como "nolugares". Es decir, hasta ese momento, a pesar de las sucesivas señales de mi interlocutor, no encontraba en los bares positividad alguna y, por lo tanto, operaba en mí una fuerte visión etnocéntrica que -como sostienen Alejandro Grimson y Pablo Semán (2007) en su crítica a la citada obra de Augé- no contemplaba las transformaciones culturales y las propias perspectivas de los participantes de esos escenarios. Por el contrario, 
estos autores afirmaron que "el antropólogo debe dejarse interpelar por los sujetos que estudia. Escribir sus observaciones hasta que la densidad de las mismas restituya algo más que su prejuicio y pueda rasgar sus teorías previas" (Grimson y Semán, 2007, p. 76).

Efectivamente, la sumatoria de los registros de campo fue la que modificó aquel parecer que me indicaba que en las entrevistas en los bares escucharía a Marcos hablar sobre política, pero que jamás podría observar allí su modo de hacer política. Aparecía, entonces, una distinción donde, por un lado, los bares se convertían en los sitios para inmiscuirme en el discurso político de mi interlocutor y, por el otro, las manifestaciones devenían en los espacios indicados donde observar su puesta en práctica. En este sentido, me ocurría algo similar a lo planteado por Sabina Frederic (2000) respecto a que su participación en diversas reuniones entre gobernantes y gobernados le hacían pensar, en un primer momento, que "lo importante sucedía fuera de estas formas de interacción; que la realidad política se desarrollaba más allá de este tipo de encuentros y sus características rozaban el oscuro terreno de lo prohibido" (p. 198). Afortunadamente, el transitar con Marcos ese espacio me permitió ver que "la política" lo acompañaba a cada lugar que iba y que, por lo tanto, no había que ir a buscarla como algo exógeno a determinados lugares asociados frecuentemente a ella. Así, los bares que hasta aquí eran "no-lugares" donde llevar adelante las entrevistas, adquirían un lugar central, al igual que lo fueron para el trabajo de Eduardo Archetti (1999) en sus conversaciones sobre futbol con sus informantes ya que en ambos casos eran parte de los entramados cotidianos de los entrevistados. Como se puede ver con el siguiente fragmento, Marcos le otorgaba centralidad a los bares desde la primera entrevista que le realicé:

Tuvimos casi un año de trabajo por decir de alguna manera "clandestino", nos reuníamos en este bar, a tres cuadras de la fábrica, para que no se enteren los buchones. Al principio nos reunimos tres, después cuatro, después cinco, después seis, hasta que tuvimos que cambiar de bar por uno más lejos y más grande porque llegó un momento que éramos treinta y hasta cincuenta (Marcos, Comunicación personal, 18 de julio de 2016).

Sin embargo, logré dimensionar la importancia de este espacio con el transcurrir de las entrevistas al sorprenderme por la soltura con la que se desenvolvía en ellos. Algunos eran los "históricos" en los que comenzó el proceso de politización fabril y otros eran más recientes, pero no por ello menos familiares para él, como repararemos a continuación.

\section{III. "AHORA QUEREMOS QUE NOS VOTE GENTE QUE NO NOS CONOCE"}

Lo interesante del bar como espacio para las entrevistas es que permitía ver a Marcos en otro entramado sin las claras jerarquías existentes al interior de la agrupación gremial -donde su rol de liderazgo era notorio- y sin las propias del partido. Parecía, entonces, ser un lugar más neutral para comprender, en un contexto de campaña electoral, su modo de proseguir el objetivo de todo partido: juntar votos. Detengámonos en lo acontecido en el bar de Rosa antes de prender el grabador y comenzar "formalmente" la entrevista de ese día. Marcos me comienza a contar que estaba con muchísima actividad por la campaña de las PASO y que estaba siendo muy diferente a la de otros años porque por primera vez se habían "asesorado" con una "consultora" para saber en qué zonas de La Matanza se localizaban sus votantes. La semana anterior había ido a una reunión donde los "consultores" habían llevado un mapa del distrito que mostraba en color magenta los lugares de donde podrían obtener más votos. Por lo tanto, tendrían que concentrar su militancia en esas zonas y no gastar tiempo y recursos en los lugares donde el peronismo sacaba más del 70\% de los votos, como sucede siempre en "los kilómetros", en referencia a González Catán y Virrey del Pino. Al escucharlo hablar, se percibía que recordaba ese mapa a la perfección en su cabeza y se ayudaba con sus manos para señalarme -en el aire- las áreas privilegiadas. Le pregunté si esa información era muy distinta a la que ellos tenían, me dice que no, que ya sabían en qué barrios les había ido bien en la elección pasada. Pero que le parecía importante contar con "un estudio" de esa índole para pensar mejor la campaña ya que en relación a elecciones anteriores la posición del partido había cambiado mucho: "antes cada militante llevaba la propuesta del partido a sus allegados, familia, 
amigos y trabajo e instábamos conseguir ese voto" y, en cambio, "ahora queremos que también nos vote gente que no nos conoce”. Es decir, se proponían aumentar el número de electores y, para ello, las redes sociales y los medios de comunicación serían fundamentales. Mientras recordaba cómo militaban las campañas electorales unos años antes se rió con cierta inocencia por lo "artesanales" que eran. Parecía, entonces, que ahora la campaña se profesionalizaba y que, por ende, había que estar atento a otros aspectos.

Vale traer a colación que en 2001, Ana Rosato y Julieta Quirós (2004) ya describían con claridad las diferencias entre el Partido Justicialista y un partido de izquierda a la hora de desarrollar una campaña electoral. Evidentemente, muchas de las prácticas militantes del partido de izquierda son similares a las que Marcos realizaba por esos días: recorridas por los barrios con un grupo de militantes para repartir sus propuestas políticas, montar una mesa en alguna esquina céntrica para persuadir discursivamente a los peatones, difundir boletas partidarias en los espacios de trabajo. Mientras que en el momento que Rosato y Quirós (2004) realizaron su trabajo de campo, el periódico tenía un lugar predominante para el lazo político entre el militante y el posible elector, en el partido de Marcos eso ya no tiene tanta relevancia porque apuestan al formato digital del diario. Por lo tanto, la permanente difusión de notas periodísticas a través de las redes sociales y de WhatsApp es fundamental. En otra oportunidad, Marcos me había comentado lo siguiente:

El haber hecho el diario digital para nosotros es un cambio muy grande en la militancia, porque la izquierda está acostumbrada
a pasar el periódico en papel una vez por semana y que sean todos más o menos iguales, tapa roja y negra, un poquito blanco
y termina ahí (risas). Pero el diario hay que tomarlo con más seriedad porque, por ejemplo, el periódico de los Bolcheviques
fue el que organizó la revolución, pero lo hicieron de verdad bien, no como algo rutinario (...) Hoy, al haber utilizado en
forma revolucionaria la tecnología y el diario, un diario digital, las notas llegan más allá de lo que llegan a nuestras manos.
Miles de me gusta, compartido y, a la vez, al tener secciones en donde puede escribir cualquier persona sea o no sea de nuestra
ideología, pueden ser obreros, estudiantes, amas de casa, lo que sea, se arman debates en los cuales interactúan otras personas
que no necesariamente son militantes, pero por ahí le interesó una nota entera, o parte de tu nota y a partir de eso abrís una
nueva discusión que puede llevarte o no al acercamiento en ideas, o por lo menos tenerlo como amigo (Marcos, comunicación
personal, 26 de agosto de 2016).

El diario continuaba siendo central, pero comprendían que en formato papel encontraba fácilmente un techo de lectores. En muchas oportunidades, Marcos me planteaba que, desde la conformación del FIT en 2011, tenían que proponerse una estrategia más amplia para llegar a todos sus votantes. Por lo tanto, el diario digital, con temáticas diversas y “más moderno”, sin el clásico diseño de los diarios trotskistas, parecía ser una buena respuesta.

Marcos es un asiduo escritor del diario, ha publicado más de cuarenta notas. Muchas de ellas describen el día a día de la fábrica -momentos de elecciones, accidentes laborales, denuncias al accionar del sindicato, conquistas de la comisión interna, adhesión a paros, vinculación con otras fábricas- pero también hay un interesante corpus en relación a fenómenos musicales -homenajes a bandas de rock, crónicas de los recitales, difusión de discos de bandas pequeñas, entrevistas a los músicos de bandas barriales-. En su caso el uso del teléfono para redactarlas es algo habitual: aprovecha los pequeños ratos libres del trabajo para realizarlas. Este modo de escribir es, para él, algo positivo, porque al evitar que las personas tengan que hacerlo en computadora lo hace más participativo. En esta misma línea, destaca que, incluso, es posible enviar la idea de la nota en un mensaje de voz de Whatsapp y alguien del staff del diario la trascribe. Por otra parte, en el relato de Marcos nos encontramos que el diario no significa solamente la oportunidad de difundir ideas o de motivar discusiones políticas, sino que también interviene en la vinculación cotidiana con sus compañeros de trabajo ya sea para compartirles contenido como para invitarlos a que "se animen a escribir". Así, marca como un gran logro que obreros que se encontraban alejados de prácticas de escritura, tuvieran una participación en el diario:

Cacho ya me dijo que tenía una nota escrita y que me la iba a mandar, después hay otro que escribe poesías, se llama Tincho... el chabón es anarquista, antipartido, sin embargo, escribe en nuestro diario. Después se arma el debate... El otro día otro de los delegados escribió sobre el club de Morón porque hay una sección de deporte. Yo la otra vez escribí una nota de los 
quince años del último recital de los Redondos y así cada uno hace lo que más le gusta para que no sea un diario rutinario (Marcos, comunicación personal, 26 de agosto de 2016).

De esta manera, las transformaciones que Marcos relataba aquel día, en el bar de Rosa, en torno a estrategias para aumentar el volumen de electores, se vinculaban con las que ya señalaba hacía tiempo. En efecto, si el diario, desde su perspectiva, continuaba promoviendo la discusión política en pos de lograr un acercamiento en las ideas con otras personas, es también interesante su valoración de lograr otro de tipo de proximidad -a través de la diversidad de temáticas y por medio de la convocatoria a escribir allí- y el simple hecho de "tenerlo como amigo" en las redes sociales. Con respecto a ellas, Marcos era sumamente activo: en cada movilización que lo acompañé sacaba fotos y, al instante, las "subía” a Facebook y, más de una vez, transmitía en vivo. Así, me mostraba que "estar en las redes" era también importante.

Entonces, si en Rosato y Quirós (2004) la discusión aparecía como la actividad partidaria por excelencia como pauta de interacción en el partido de izquierda estudiado, veremos que si centramos la mirada en un militante como Marcos nos encontraremos frente a la necesidad de matizar dicha caracterización. Cabe resaltar que, un año atrás, él ya me indicaba que la militancia debía buscar otras estrategias para lograr nuevos simpatizantes y que, por ende, la discusión políticano podía ser la única opción. En este sentido, al verlo interactuar en los bares, podía comprender que la búsqueda de cercanía que mencionaba en las redes sociales también la ponía en práctica en esos espacios y, por esta razón, los mismos eran fundamentales en su perspectiva y dignos de ser estudiados. Por consiguiente, vale describir, el intercambio entre Marcos y la dueña del bar para profundizar el argumento.

\section{IV. "Nos ESTÁN MATANDO MÁS QUE CON EL VOTO EN BLANCo"}

Luego de hablarme sobre aquel estudio de la consultora, Marcos mostró mucha preocupación por un hecho que había ocurrido el día anterior: la votación en el Congreso de la Nación a favor de la expulsión de un diputado acusado de cometer delitos de corrupción bajo los gobiernos kirchneristas ${ }^{2}$. La intranquilidad de Marcos radicaba en que el partido había decidido votar en contra de dicha medida, al igual que el bloque del Frente para la Victoria (FPV), y a pesar de estar de acuerdo con el partido, entendía el riesgo que implicaba: "nos estaban matando más que con el voto en blanco". De esta manera, comparaba las críticas que había recibido con las que emergieron cuando llamaron a votar en blanco públicamente en el ballotage presidencial del 22 de noviembre de 2015 que enfrentaba al candidato Daniel Scioli, por el FPV, y a Mauricio Macri, por Cambiemos. En ese contexto, el FIT había recibido duros ataques, por ende, la equiparación que Marcos realizaba significaba, en parte, la intensidad de los comentarios que habría recibido de su entorno y en las redes sociales. En relación a la dificultad de "militar" el voto en blanco planteaba, en una entrevista del año anterior, lo siguiente:

En la fábrica fue así como en todos lados... Acá la mayoría vota a Scioli, aunque hubo muchos compañeros que votaron a Macri en el ballotage. O sea, todos por odio contra el otro, muy pocos porque estaban convencidos... Nosotros les dijimos que estábamos llamando a votar en blanco y “noooo, tenés que jugártela por alguien”, nos decían. Como en todos lados... nosotros tuvimos un montón de votos en las PASO porque hubo tres compañeros de la fábrica que fueron candidatos para nuestra lista. Y hubo compañeros que hicieron campaña adentro y en los barrios, y bueno nos fue bien... después en las finales también nos votaron, en las de octubre, pero en el ballotage no. Ahí, voto en blanco olvidate, habrán votado cinco personas de toda la fábrica, con toda la furia (Marcos, comunicación personal, 26 de agosto de 2016).

En la misma sintonía, otro de los trabajadores de la fábrica y militante del mismo partido afirmaba:

Entre 70 y 80 trabajadores votaron al FIT, eso en las PASO (...) Después en el ballotage, la mayoría votó por el cambio y otros por el menos peor, nadie votó conscientemente de quién podía venir. El voto en blanco era durísimo, porque también los medios ayudaban a que es uno o el otro (Diego, comunicación personal, 30 de noviembre de 2016). 
Resulta enriquecedor ver que estas interpretaciones basadas en el microcosmos de la fábrica tenían su correlación con los porcentajes definitivos de la elección. Como bien sostiene Adriana Gallo (2017), la campaña del FIT de cara al ballotage no resultó satisfactoria ya que, por un lado, la tasa de voto blanco y nulo fue bastante inferior que la registrada en las elecciones generales de octubre y, por el otro, menos de un tercio de los electores de la lista presidencial del FIT habría votado de este modo en la segunda vuelta. Es importante, entonces, dimensionar lo que significó esa experiencia de militancia electoral, más aún cuando mi interlocutor la utiliza para marcar un paralelismo con la situación que atravesaba por esos días y que le provocaba preocupación. Por lo tanto, la asimilación entre el momento del voto en blanco y la votación en contra de la expulsión del diputado denotaba que ambos fueron contextos de mucha repercusión mediática respecto a las decisiones que tomaban desde el FIT y que, por ende, también emergían las críticas recibidas por los militantes en lugares de trabajo y entornos cercanos. Además, un dato no menor es que ambos fueron en períodos electorales y, por tal, debían desarrollar su actividad militante para captar votos a la par de estos cuestionamientos.

Aquel día en el bar me comentó que la consultoraevaluó las repercusiones mediáticas que podía tener a quince días de las PASO- votar en contra de la expulsión del diputado y que, finalmente, les recomendó optar por la abstención, pero "el partido" no consideró adecuada esa opción. Mientras seguimos conversando, llegó Santi, el hijo de Rosa, de unos treinta años. Se acercó a saludarnos, muy cariñosamente, y ahí Rosa aprovechó la interrupción para manifestarle a Marcos que estaba indignada con lo que hizo el día anterior "su partido", no entendía "cómo defendieron a ese corrupto, estaría a favor de ustedes si defendieran lo que tienen defender”. A partir de ahí, se desató una acalorada discusión entre ambos. Marcos le intentó explicar por qué votaron de esa forma, pero Rosa estaba poco predispuesta para escuchar sus argumentos -que eran similares a los que habían dado los públicamente los candidatos-. Ciertamente, aquí la discusión política no logró ser un buen recurso ya que ella estaba muy firme con su opinión y, por ende, la explicación de Marcos nada modificaría. A pesar de estas críticas, insistía en que si no hubiera sido por eso los habría votado, porque sabía que son gente honesta y que Marcos es un reflejo de eso.

Así, la incomprensión transmitida por Rosa con "el partido de Marcos" mostraba la centralidad que adquieren las valoraciones morales en los vínculos de los militantes políticos y los posibles electores. En este sentido, la etnografía de Frederic (2004) sostiene que las evaluaciones morales deben estar presentes en los análisis sobre política, esencialmente, porque tienen el poder de influir en las acciones futuras de las personas. Es decir, a raíz de esos momentos de la práctica en los que los sujetos interpretan las acciones ajenas o bien juzgan sus resultados, guían sus próximos comportamientos. De este modo, la autora advierte que la política y la moralidad, lejos de ser esferas separadas, se encuentran fuertemente imbricadas en las dinámicas de poder. Por lo tanto, "al atender el ajuste y desajuste entre evaluaciones morales en la práctica misma, los procesos políticos se hacen inteligibles, en el sentido de permitirnos descubrir aspectos imprevistos de los mismos" (Frederic, 2004, p. 42).

Es por ello que retomar la discusión entre Marcos y Rosa con los aportes de esta perspectiva nos permite reflexionar sobre varios aspectos. En primer lugar, podemos interpretar que, hasta aquí, para Rosa el partido de izquierda al que Marcos pertenece era considerado respetable debido a las características personales de él. En otras palabras, había cierta correlación entre los criterios morales de Marcos y el partido: que él fuera honesto, trabajador, afectuoso y comprometido hacía que el partido adquiriera, en parte, esos atributos debido a que él era para ella su referencia de "la izquierda". Sin embargo, vemos que su opinión cambió rotundamente con la aparición en los medios de comunicación de aquella escena legislativa. La honestidad de Marcos ya no era una garantía: acompañar en el Congreso de la Nación "al corrupto" hacía que, a sus ojos, fueran contradictorios y "no estuvieran donde tenían que estar", ¿̇acaso cuál era ese sitio del "deber ser"? Dado que el deseo de Rosa se manifestaba en la expulsión del diputado en cuestión -una figura fuerte del kirchnerismo- modificó drásticamente su evaluación moral respecto al partido "de Marcos" por ir en contra de ese objetivo. En este sentido, Frederic (2004) retoma a Eduardo Archetti para afirmar que los individuos 
al construir sus razonamientos en relación a determinados campos de acción desde los sentimientos, el deseo y la imaginación, se comportan moralmente. De esta manera, al vincular moralidad y deseo, vemos cómo la etnomoralidad reconoce en los agentes la capacidad de elegir entre argumentaciones morales y, así, contempla la capacidad de agencia y cambio. En efecto, Rosa, a raíz de su interpretación de los hechos, había decidido modificar su parecer sobre este partido y, por lo tanto, fue explícita en que no los acompañaría electoralmente.

Esta discusión reflejaba con claridad que la preocupación de Marcos al entrar al bar tenía, sin dudas, anclaje en la realidad social, no era una mera percepción sobre los difundidos ataques a la izquierda que realizaron diversos periodistas acusándolos de ser "funcionales a la corrupción". Su bronca residía en la capacidad que había tenido el gobierno, en plena coyuntura electoral, de obligarlos a posicionarse con respecto a un tema que los incomodaba porque sabían sus costos. Incluso, la consultora se los había advertido. De esta manera, vemos que la temática de la corrupción inhabilitaba por completo tanto la posibilidad de llevar adelante una discusión política como de capitalizar la cercanía que Marcos había construido en su relación con Rosa. Si en circunstancias donde las demás personas no coincidían con sus lineamientos políticos, Marcos mostraba que contaba con atributos personales para -desde el afecto, la empatía, el humor y el encarnar valores de esfuerzo y trabajo- lograr que sus interlocutores transfirieran esas consideraciones positivas sobre su persona hacia "el partido". Seguramente, esta "jugada" del gobierno de presentar el proyecto de expulsión de este diputado a dos semanas de las elecciones primarias lo preocupaba porque ponía en cuestión justamente esos principios morales que les servían para acercarse a personas como Rosa con opiniones muy alejadas a las de "la izquierda".

En efecto, es razonable pensar que en contextos de alta intensidad política con temáticas que despiertan una fuerte polarización, como puede ser el voto en blanco o haber apoyado a un diputado acusado de corrupción, la forma de militar de Marcos en sus entornos cotidianos, como los bares, encuentra ciertas dificultades a las que, como buen militante, jamás se rinde. Por lo tanto, aquí es esencial tener presente la noción de determinación de Raymond Williams (2009) que nos propone pensar los contextos en los cuales los sujetos se mueven como fijación de límites y, a la vez, ejercicio de presiones. Con esta concepción jamás perderemos de vista que las personas siempre actúan a pesar del estrecho abanico de posibilidades que se les presenten. Si hasta aquí Marcos mostraba que la cercanía y el afecto eran buenos recursos para aproximar "el partido" a quienes se encontraban alejados políticamente de él, los escenarios con un alto grado de polarización entre el kirchnerismo y el gobierno de Cambiemos lo enfrentaba a un gran desafío donde, como vimos, el ser un representante de ciertos valores morales no era garantía para guiar el comportamiento político. Y, más allá de que este modo no haya resultado efectivo con Rosa, ello no implicaba que se diera por vencido con los demás que quedábamos ese día allí.

\section{ReFleXividADES EN ACTO}

Al apagar el grabador, luego de una hora y media de entrevista, nos quedamos conversando con Santi sobre su decisión de irse a vivir a Barcelona y, finalmente, lo invitó a Marcos a su despedida que organizaría el siguiente fin de semana en su casa. Nuevamente, el asombro me invadía y me preguntaba cómo lograba que personas como Santi o, en su momento, "los viejitos" sintieran tanto grado de cercanía con él, en los ratos que compartían en sus bares, para que lo integraran a actividades de su ámbito personal como pueden ser una despedida o, más aun, un casamiento en el rol de testigo. La respuesta, fácilmente, la encontraba observando su modo de vincularse en estos sitios. Entonces, este aspecto de su personalidad, que en un principio formaba parte de una mera caracterización, ahora se tornaba central en mis registros de campo.

Luego de recibir la invitación de Santi, Marcos nos pidió que lo esperáramos unos minutos porque nos quería entregar "algo" que tenía que buscar en el auto. Volvió con tres bolsitas de plástico color rojo, le entregó una a Santi, otra a un señor habitué del bar y otra a mí. Nos dijo que se trataba del "kit del militante" para que pudiéramos difundir entre nuestros conocidos. Cada kit contenía un diario, dos posters y stickers con la imagen de los candidatos y volantes con las propuestas del partido. En relación a ello, Hélène Combes (2011) 
sostiene que, tanto "la apariencia militante" -como pueden ser gorras y remeras-y el material militante -los volantes, folletos, periódicos-, al manifestar las formas de identificación con el partido, permiten desentrañar formas de vinculación política. Por lo tanto, el kit que Marcos nos entregaba hablaba de un alto grado de organización por parte del partido en torno al material de difusión electoral y, a la vez, de una estrategia para incentivar la participación de los contactos de los militantes en campaña. Es probable que, por esta razón, hacía entrega del kit a personas que no se autoidentificaban como militantes del partido. Quizás con la recepción del mismo, nos convertíamos, para él, de modo indirecto y esporádico en ello. Si el objetivo para estas elecciones era que los votasen personas que no fueran únicamente allegadas a los militantes, la entrega del kit a otras personas podía ser una forma de, en un punto, integrarnos a la campaña política para que llegasen a círculos de individuos desconocidos. Pero en mi caso también podía ser interpretado de otro modo.

Aquí cabe mencionar que Laura Colabella (2006), a raíz de reflexionar acerca de un incidente ocurrido en su trabajo de campo, sostiene que las amenazas recibidas por parte de sus interlocutores reflejaban cierto malestar en torno a su lugar de observadora. La investigadora había participado de una reunión de los miembros de la organización social que estudiaba y aquel día observó el modo en que le realizaban una brujería a una integrante de la organización que no estaba presente. Entonces, para que Colabella mantuviera el silencio por lo que había visto, la amenazaron. Así, le hacían sentir que la brujería también podría alcanzarla y que, por ende, no había lugar para simples observadores con el fin de "conocer". En efecto, si en esta situación la amenaza significaba que la brujería podría llegar también a ella, en este caso, el kit podía representar que la militancia podría alcanzarme. En ambos casos, en situaciones radicalmente distintas, nuestros interlocutores nos quitaban del lugar de meras observadoras.

No era la primera vez que Marcos me hacía notar cierta insatisfacción con mi rol. En la tercera entrevista que le realicé me puso la condición -con su característica simpatía y soltura- que, al terminarla, él me haría una entrevista sobre mis intereses por el proceso de sindicalización gremial. En ese momento, a la luz de la lectura del clásico artículo "Shakespeare en la selva" de Laura Bohanann (2004), comprendía dicha situación como la necesidad que, muchas veces, tienen nuestros interlocutores de invertir los roles y ser ellos quienes preguntan para escuchar nuestras opiniones sobre determinados temas. En otra oportunidad, me invitó a un acto político del partido al que, por la fecha, no podría asistir, y ante mi explicación manifestó su molestia porque, según él, iba a ser un momento central para mi investigación. Así, él pretendía asumir mayor protagonismo y determinar qué era "lo importante" para mi trabajo.

A raíz de ello, mi interpretación inicial se vio rápidamente modificada: estaba claro que Marcos, con aquella entrevista, me exigía posicionarme políticamente y, luego, con su insistencia para que acudiera al acto, me mostraba su inconformidad con que no me asumiera como una investigadora-militante. Por lo tanto, la entrega del "kit del militante", en mi caso, no podía ser leída aisladamente. De este modo, la interpelación de mi interlocutor que me obligaba a repensar, persistentemente, mi rol en el campo, también me indicaba algunas claves más para comprender su militancia. No entendía por qué me provocaba tanto asombro su capacidad de generar confianza rápidamente con personas que conocía desde hacía poco tiempo, si mi vínculo con él también había sido de esa manera. Por otra parte, mi extrañamiento denotaba que comparaba sus temporalidades con las mías para entablar relaciones. Evidentemente, hasta que no me dejara inmiscuir por su propia noción temporal, poco comprendería.

Así, al recordar su forma de relacionarse conmigo ni bien nos conocimos, me hacía dar cuenta que había sido similar a lo ocurrido con las personas de los bares, excepto que yo -a diferencia de Santi y "los viejitos"no lo había hecho partícipe de mi entorno más privado. Por lo tanto, al dimensionar la importancia que tenía la cercanía en su forma de vincularse como militante, entendí que la entrevista, su enojo y el kit podían ser comprendidos como modos de cuestionar mi distancia en algunas situaciones. De este manera, quedaba en claro que la reflexividad lejos está de ser un atributo de quien investiga ya que se trata de una propiedad del mundo social (Colabella, 2014) y que, por ende, nuestros interlocutores también recurren a ella para hacerse preguntas sobre sí mismos y sobre los demás. En este sentido, Quirós (2014) nos invita a 
corrernos de la noción limitada de reflexividad -que comprende únicamente las situaciones de comunicación verbal con el investigador- para pensarla y trabajarla en acto. Para ello, resulta primordial concebir que las personas se aferran, cotidianamente, a explicaciones, atribuciones de intención y justificaciones sobre la acción propia y también sobre la de los demás (Quirós, 2014). En mi caso, entonces, para interpretar las actitudes de Marcos, necesitaba, urgentemente, ser consciente de la reflexividad que él desarrollaba sobre mi persona. Para ello, debía asumir la política como categoría etnográfica en la cual, siguiendo a Peirano (1997), observadores y observados somos tanto "nativos" como "investigadores" (citado en Ferraudi Curto, 2011). Por lo tanto, retornar a mi casa, aquel día, con el "kit del militante” me abría un sinfín de preguntas que, para encontrar respuestas, necesitaban de un momento de pausa para revisar el camino recorrido hasta aquí con mi interlocutor.

\section{VISITAR Y DISCUTIR: ANTE LA NECESIDAD DE PENSAR NUEVAS TIPOLOGÍAS}

Sin lugar a dudas, el estudio comparativo de Rosato y Quirós (2004) sobre las prácticas militantes de un partido de izquierda y del Partido Justicialista en la campaña electoral de octubre de 2001 resulta más que iluminador para pensar la forma de militancia de Marcos. Las autoras sostienen que, por un lado, se encuentran los militantes de izquierda con la creencia de que la discusión -en tanto práctica transmisora de conocimiento- es la forma más efectiva para lograr la adscripción política de sus interlocutores y orientar su elección y, por el otro, están los militantes peronistas que le adjudican centralidad a la práctica de la visita porque piensan que a través de la creación y reactualización de compromisos personales basados en intercambios recíprocos está la base de la decisión política del elector. En nuestro caso, al centrar la mirada únicamente en la militancia de Marcos, vemos que, a pesar de estar encuadrado partidariamente, su comportamiento en los bares rompe con las formas más esquemáticas de hacer campaña implementadas por el partido. Al ver la importancia que adquieren los criterios morales sobre su persona y su forma afectiva de relacionarse, la diferenciación entre las prácticas de discutir y de visitar se torna más borrosa.

Pareciera, entonces, que Marcos entiende muy bien que el comportamiento político del mundo social no sólo descansa en la discusión política, sino que también hay otros aspectos que provocan cercanía. Desde su mirada, entonces, podemos comprender que la transformación del diario, mencionada anteriormente, iba en esa sintonía. Al mismo tiempo, al escoger los lugares, Marcos me hacía ver que su forma de hacer política no se acotaba a los espacios tradicionales de la actividad como el gremial y el partidario y que, también, desde su empatía con las personas en los bares podía tejer amistades a las que, en momentos de elecciones, podía acudir para acercarles la propuesta del partido. Los comentarios sobre su persona de "los viejitos del bar" y de Rosa y Santi me permitían percibir que Marcos representaba la idea de un ser honesto, trabajador, comprometido y, por sobre todo, "buena gente" y, al mismo tiempo, su constante empatía con los demás le permitía generar lazos de confianza a los cuales podía acudir en momentos de campaña para -directa o indirectamente- solicitar votos. Con respecto a ello, la esposa de un ex trabajador de la fábrica que fue despedido y al que Marcos ayudó personalmente, me comentaba en una entrevista que, desde entonces, ella votaba "a los izquierdistas de Marcos". De este modo, se veía que para esta mujer la referencia de "la izquierda" era Marcos y votarlos era uno de los modos de agradecerle la ayuda otorgada a su marido.

Por lo tanto, las nociones morales positivas que giraban en torno a su persona, le permitían no sólo tener amistades en cualquier lugar que iba, sino que también le resultaban favorables para el partido. Claro que esta imagen sobre él es una fiel respuesta a su genuina forma de entablar relaciones interpersonales, pero también podemos pensar que, por un lado, su condición de obrero fabril -con turnos rotativos y pocas horas de descanso- lo hacía encarnar el ideal de sacrificio y, por el otro, su recurrente afirmación respecto a que el partido se autofinanciaba reforzaba la idea de honestidad y transparencia. Por esta razón, podemos pensar que un militante de izquierda como Marcos podía interpelar partidariamente inclusive a personas como Rosa hasta que, como vimos, un caso de corrupción modificaría su evaluación sobre la concepción moral del

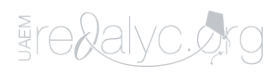


partido. De esta manera, se entendería la necesidad de comprender la política como una práctica que está mediada continuamente por valores morales (Frederic, 2004).

En suma, prestar atención a estas sociabilidades nos permite repensar en nuestros contextos las tipologías de la militancia y dilucidar algunas líneas de continuidad y ruptura. Así, al igual que el militante comunista francés de décadas pasadas que sustentaba su legitimidad en el hecho de provenir del mismo medio social de las personas a las que representaba y, a la vez, pertenecer a una red política más amplia (Pudal, 2011), el caso de Marcos nos muestra que, claramente, ser delegado de base le otorga legitimidad entre sus compañeros de fábrica y esto, asimismo, es reconocido positivamente en su ámbito partidario. En este sentido, "el delegado funciona bajo la doble mirada y reivindicando una doble lealtad: la de los compañeros del taller y la de los compañeros del grupo militante con quien se identifica cada vez más" (Beaud y Pialoux, 2015, p. 316). Sin embargo, para comprender la militancia de Marcos es fundamental dar cuenta de la existencia de otras redes que no se limitan a estos ámbitos; que emergen de los lugares que transita en su día a día y que probablemente sean más inestables, pero que también aúnan a su crecimiento como militante ya que, siguiendo a Sawicki (2011), forman parte del conjunto de relaciones personales que conforman su capital social. Por lo tanto, detenernos a reflexionar sobre sus formas de vincularse en los bares nos permite pensar que allí también su capital militante es ampliado ya que, como bien sostiene Poupeau (2007), este "designa, más allá de la diversidad de las formas de compromiso, un saber-hacer adquirido, en particular gracias a propiedades sociales que permiten jugar, con mayor o menor éxito, en un espacio que está lejos de estar unificado" (p. 44). En definitiva, resulta indispensable tener presente el planteo de Beaud y Pialoux (2015) respecto a que, a través de intercambios de representaciones y de afectos, ciertos militantes logran destacarse. Así, el sistema de dones y contra-dones de intercambios simbólicos es el fundamento de las redes en las que está inserto.

\section{REFLEXiOneS FiNALES}

Como desarrollamos a lo largo de estas páginas, recuperar la noción de persona para el estudio de los procesos de sindicalismo de base resulta enriquecedor para comprender, con mayor profundidad, quiénes son los principales referentes. En este caso tratamos de explicar que, para tener una visión lo más integral posible de Marcos, no alcanzaba con trabajar con los registros de campo respecto a su actividad gremial o partidaria ya que, en las entrevistas, él mismo mostraba que un militante como él está en movimiento en los distintos espacios que transita para fortalecer, a fin de cuentas, "al partido". Por esta razón, fue indispensable recuperar aquellas sociabilidades que suceden en los bares matanceros debido a que, a través de ellas, se podía vislumbrar con claridad la capacidad de Marcos de relacionarse y aumentar su capital social, fundamental para desplegarse como militante.

En este sentido, él me mostraba que algunos lazos personales -como los de sus compañeros de fábrica e integrantes de su familia- podían también reconvertirse en lazos militantes ya fuera, en el mejor de los casos, cuando pasaban de ser "contactos" a militantes, pero también con su presencia en aquellos acontecimientos importantes para el partido como podían ser actos, movilizaciones como las del primero de mayo o los días de las elecciones en los que requerían de una gran cantidad de fiscales. En esos eventos que demandaban gran convocatoria, Marcos demostraba que tenía la capacidad para que sus allegados estuvieran ahí "dándole una mano". Es factible presumir que detrás de ese "favor" había un largo proceso anclado en lo afectivo y mediado por criterios morales. Entonces, si él en los bares podía pasar de ser un simple cliente a un testigo de casamiento o a un amigo que participa de una despedida, no era descabellado concebir que esas personas también podían transformarse en un apoyo para su militancia -ya sea más pasivamente como simples votantes o con una participación eventualmente más activa---. La discusión con Rosa reflejaba las limitaciones, en contextos polarizados, de esa forma de militar y, por lo tanto, le presentaba grandes desafíos.

Por otra parte, quedó en claro que reconstruir estos aspectos sobre su forma de hacer política implicó, necesariamente, una introspección sobre mi lugar en el campo para dimensionar que yo también me 
encontraba dentro de su red y que, por ende, nuestro vínculo debía ser objeto de reflexión. Como quedó de manifiesto, la reflexividad no es atributo exclusivo del investigador, sino que, en este caso, fue él quien se apropió primero de ella para sacar conclusiones sobre mis conductas. Probablemente, sin nunca haber leído los aportes de la antropología política, él entendía a la perfección que si era observado también le cabía el rol de investigador, mientras que yo -a pesar de conocer aquella perspectiva- no llegaba a asir que, si era investigadora, indefectiblemente, estaba sujeta a su observación.

Finalmente, haber puesto el foco en Marcos implicó dar cuenta de que los militantes trotskistas no sólo discuten para hacer política, sino que también tejen vínculos personales basados en la confianza, la empatía y el afecto, que indefectiblemente resultan indispensables en su construcción política.

\section{REFERENCIAS}

Abal Medina, P. (2014). Ser sólo un número más: trabajadores jóvenes, grandes empresas y activismos sindicales en la Argentina actual. Ciudad Autónoma de Buenos Aires: Biblos.

Abélês, M. (1997). La antropología política: Nuevos objetivos, nuevos métodos. Revista de Ciencias Sociales, 153, 22-63.

Aiziczon, F. (2009). Zanon, una experiencia de lucha obrera. Buenos Aires: Herramienta \& El Fracaso.

Archetti, E. (1999). Hibridación, pertenencia y localidad en la construcción de una cocina nacional. En Altamirano, C. (Comp.), La Argentina en el Siglo XX (pp. 217-235).Buenos Aires: Editorial Ariel.

Augé, M. (1992). Los no lugares: espacios del anonimato. Una antropología de la sobremodernidad. Barcelona: Gedisa Editorial.

Beaud, S. y Pialoux, M. (2015). Repensar la condición obrera: Investigación en las fábricas de Pengeot de SochauxMontbéliard. Ciudad Autónoma de Buenos Aires: Antropofagia.

Benza, G. (2016). La estructura de clases argentina durante la década 2003-2013. En La sociedad argentina hoy: radiografía de una nueva estructura (pp. 111-139). Ciudad Autónoma de Buenos Aires: Siglo Veintiuno Editores.

Bohannan, L. (2004) [1966]. “Sheakespare en la selva”. En Boivin, M., Rosato, A. y Arribas, V. (eds.), Constructores de otredad. Una introducción a la Antropología Social y Cultural (pp. 75-80). Buenos Aires: Antropofagía.

Colabella, L. (2014). O te vamos a ir a buscar. Un caso de brujería en los límites de la observación participante. En Practicas etnográficas: ejercicios de reflexividad de antropólogas de campo. Buenos Aires: Instituto de Desarrollo Económico y Social.

Combes, H. (2011). “Tomar partido”. Para una sociología de los militantes desde los cierres de campaña. Revista de Sociologia, 25, 113-138.

Elias, N. (2008). Sociología fundamental. Barcelona: Gedisa Editorial.

Ferraudi Curto, M. C. (2011). ¿Estás nervioso? Las elecciones desde una villa del Gran Buenos Aires. Athenea Digital. Revista de pensamiento e investigación social, $11(3)$.

Frederic, S. (2000). De reunión en reunión: la observación participante en el conocimiento etnográfico de procesos políticos “urbanos." Horizontes Antropológicos, 6(13), 195-216.

Frederic, S. (2004). Buenos vecinos, malospoliticos: moralidad y política en el Gran Buenos Aires. Buenos Aires: Prometeo Libros.

Gallo, A. (2017). Un paso decisivo. Los partidos de izquierda después de la reforma electoral en Argentina. Revista POSTData: Revista de Reflexión y Análisis Politico, 22(1), 233-271.

Goldman, M. (1999). Alguma antropologia. Rio de Janeiro: Relume Dumará: Núcleo de Antropología da Política.

Grimson, A., y Seman, P. (2007). Los no-lugares: una criatura etnocéntrica. KONVERGENCIAS. Filosofía Y Cultureas En Diálogo, IV(15), 74-76.

Pereyra, S. (2016). La estructura social y la movilización: conflictos políticos y demandas sociales. En La sociedad argentina hoy: radiografía de una nueva estructura (pp. 233-255). Buenos Aires: Siglo Veintiuno Editores. 
Poupeau, F. (2007). Dominación y movilizaciones. Estudios sociológicos sobre el capital militante y el capital escolar. Cordoba-Argentina: Ferreyea Editor.

Pudal, B. (2011). Los enfoques teóricos y metodológicos de la militancia. Revista de Sociología, 25, 17-35.

Rosato, A., \& Quirós, J. (2004). De militantes y militancia: el trabajo de dos partidos políticos en las elecciones legislativas de 2001 en Argentina. En C. C. Teixeira y C. de Alencar Chaves (Eds.), Espaçose Tempos da Política. Rio de Janeiro: Relume Dumará.

Sawicki, F. (2011). Para una sociología de los entornos y de las redes partidistas. Revista de Sociología, 25, 37-53.

Semán, P. y Ferraudi Curto, M. C. (2013). La politicidad de los sectores populares desde la etnografía: ¿más acá del dualismo? Lavboratorio, 25, 151-165.

Senen González, C., \& Del Bono, A. (2013). La revitalizacion sindical en Argentina y sus heterogeneidades culturales. San Justo: Universidad Nacional de La Matanza.

Varela, P. (2015). La disputa porla dignidad obrera: sindicalismo de base fabril en la zona norte del Conurbano bonaerense 2003-2014. Buenos Aires: Ediciones Imago Mundi.

Ventrici, P. (2012). Sindicalismo de base en la Argentina contemporánea (Tesis doctoral). Facultad de Ciencias Sociales, Universidad de Buenos Aires.

Quirós, J. (2005). Sobre el tiempo en la política: Notas etnográficas de la militancia en un partido de izquierda. Intersecciones en Antropologia, (6), 199-209.

Quirós, J. (2014). Etnografiar mundos vívidos. Desafíos de trabajo de campo, escritura y enseñanza en antropología. Publicar, XII(XVII), 47-65.

Williams, R. (2009). Marxismo y literatura. Buenos Aires: Las cuarenta.

\section{Notas}

1 Se trata de las elecciones nacionales Primarias Abiertas Simultáneas y Obligatorias realizadas cada dos años para seleccionar los candidatos -ya sean del nivel ejecutivo o legislativo- y a los partidos políticos que superen el 1,5\% de los votos válidos emitidos en el distrito, los cuales competirán en las elecciones generales.

2 El 26 de julio de 2017, el Congreso de la Nación sesionó para votar a favor de la expulsión del, por entonces, diputado nacional y ex Ministro de Planificación Julio De Vido. La bancada oficialista de la Alianza Cambiemos consiguió la mayor cantidad de votos, pero aun así no obtuvo los dos tercios reglamentarios para expulsarlo. El cuestionamiento a De Vido radica en una serie de causas judiciales que lo ubican como posible responsable de hechos ilícitos y de corrupción (Diario La Nación, 27 de julio de 2017). Recuperado de http://www.lanacion.com.ar/2047467-la-expulsion-a-julio-d e-vido-asi-fue-el-momento-de-la-votacion-en-la-camara 